\title{
Information Technologies in the Space of Educational Practices
}

\author{
Maryna Stryhul*, Olena Khomeriki, Marianna Khomeriki, Nataliia Polovaia and Nelia \\ Hryshchenko \\ National Aviation University, Lubomyr Huzar Ave., 1, Kyiv, 03058, Ukraine
}

\begin{abstract}
The article solves a scientific problem, the essence of which is the contradiction between the need to clarify the peculiarities of implementation of information and communication technologies in institutions of higher education of the technical profile and a certain deficit of special studies that would allow to meet this need. The situation is formulated in accordance with which in the sphere of social and cultural relations the preconditions for the use of Internet technologies are formed, but the managerial and directly educational levels of activity for the university are more promising "conservative» position, aimed at the phased and integration of these technologies in parallel processes of modernization higher education associated with the preservation of the quality of education, financial success of universities, etc. The modification of the network structure of education takes on special significance in connection with the emergence of new forms of social communication, including the innovative network learning, which becomes a social and communicative alternative to traditional education. Today, interpersonal communication, which is the sphere of the connection of new types and forms of communication without human being in the real environment, is determined precisely by the information culture of a person, which explains the human desire to learn in the new world on the basis of the use of information and computer technologies.
\end{abstract}

\section{Introduction}

Information and communication (electronic) technologies are means of influencing the growth of intellectual capital and information mobility, as their application in the educational process allows the quality of higher education through intensification of information exchange, remote access to educational resources, fundamental changes in social roles of teachers and students, social mobility in the cyberspace. The introduction of information and communication technologies in the educational process of higher education institutions of technical orientation is often limited by a number of factors that belong to the information culture of the pedagogical community, students and determine the level of their readiness to use these technologies in the educational process.

\footnotetext{
*Corresponding author: maryna.stryhul@npp.nau.edu.ua
} 
Determining this readiness becomes possible as a result of building an empirical model, indicators of which are: a) the level of relevance of the introduction of electronic technologies in the educational process of free economic zones, their significance and typical problems; b) the expediency of using e-learning for education at different educational and qualification levels; c) the effectiveness of e-learning in specific segments of higher education; d) forecasting the demand for e-higher education and its potential target audience; e) assessment of distance learning; f) assessment of virtual learning technologies by participants of the educational process; g) professional qualities of a teacher in the conditions of informatization of higher education (adaptability, flexibility, information mobility, etc.).

Higher education institutions of technical orientation in Ukraine, despite the instrumental proximity to information and communication technologies, are not always ready to implement the latter in the educational process. Organizational and culturalcommunity factors of this process are partly related to the social and professional habits of the teaching staff, which arose during previous pedagogical practices, insufficient academic mobility of teachers and students. The concretization of these factors actualizes the problem of research both in the theoretical-cognitive and in the social-practical dimensions.

The problem with the study is the contradiction between the need to clarify the specifics of the introduction of information and communication technologies in higher education institutions of technical profile and a certain shortage of special research that would meet this need. Scientific works, which reveal the problems of electronic (information and communication) technologies as a component of informatization and a tool of higher education, can be divided into four groups.

In the works of the first group, the study of the outlined topics within the framework of sociological science was carried out by such classics of sociology as M. Weber, E. Durkheim, K. Mannheim, P. Sorokin, L. Ward, and M. Scheler. The works of these authors focus on the social and cultural functions of higher education, its relationship with social, economic and political processes, its ability as a social institution to change and modernize under the influence of socio-historical situation.

In the works of the second group, the informatization of higher education is considered as a part of the theory of post-industrial (information) society. The impact of trends in postindustrial (information) society on the development of higher education, the diversity of the modernization process, inscribed in the new polysystem relations, revealed by such authors as D. Bell, K. Kerr, E. Tofler. There were publications devoted to the sociological substantiation of the new social reality that higher education was conceptualized as an environment for the transformation of consciousness through information and communication technologies [1].

In the works of the third group, in particular in the studies of D. Bock, J. Delanti, B. Clark, P. Scott, devoted to the transformation of the education system under the influence of informatization and globalization, the range of modern problems of its modernization was clearly outlined.

The works of the fourth group presented the problems of social and cultural changes in modern higher education. The development of higher education as a social institution, its modernization under the influence of social and historical development of society is reflected in the works of A. Andreev, A. Valytsky, V. Zhukov, G. Krasnozhenova, Y. Kruglov, L. Pivneva, D. Saprykin etc. 


\section{Methodology}

There were used such methods as historical and theoretical analysis. They were used to identify key concepts of Sociology of Education, their systematization and interpretation. It was used classification-typology and theoretical analysis to identify key types, directions and forms; questionnaires (as a method of collecting information) and analysis of onedimensional and two-dimensional distributions - for processing empirical data.

The empirical basis of the study includes the results of the sociological research, namely: a questionnaire survey of students (aged 18 to 24 years) (quota target sample) and teachers of 2 institutions of higher education (quota target sample).

Geography of the project - Kyiv.

The design of the project is one-stage.

Research Method - Survey.

The sample type is single-stage.

The sample size is 400 respondents.

Sampling error - $2 \%$.

The purpose of the study is to analyze the features of the introduction of e-learning technologies.

\section{Results and discussion}

Focusing on meeting mass demand, the education system today is simply doomed to have a mass of people who are dissatisfied with their education. However, we have known a way out of this situation. Educational programs and plans must become adaptive, easy to adapt not only to the requirements of the individual, but also to his educational level, to the dynamics of his learning.

This is difficult to achieve because there are state standards in education. Therefore, it will be expedient if the curricula are developed not within such a standard, but on its basis. The standard must be a minimum from which all students will start, but after graduation each of them goes his own way. Virtual learning technology is the best and most effective way to achieve this goal.

Awareness of what's in the XXI century, classical universities should start from the neoclassical technology of virtual learning, which strengthens the academic environment more and more. Today, according to the International Data Corporation, there are about 200 universities in the world that deal with the online technology of teaching their students as seriously as traditional [2]. The results do not have to wait.

In the United States alone, 710,000 people completed their higher education curricula last year alone, which is about 4.8 percent of the total number of $14,600,000$ U.S. students. There should be $14.8 \%$ of the total number of students [3].

The phenomenon of virtualization of society penetrates into the field of scientific activity. Quite often the results of scientific projects are formalized in the e-form.

Electronic publications on the Internet become the property of electronic journals and electronic libraries. Thus, the world's reserves of electronic scientific resources are constantly growing. This puts on the agenda a new large-scale problem of forming effective ways to find the information the student needs in electronic networks.

An important solution to this problem is the creation of search engines such as special types of information technology that aim to simplify the semantic search for information on various types of electronic libraries. Compared to traditional search engines that extract information based on keywords that are placed in the user's query, such as a program, first of all, tries to logically analyze the question, understand its essence and only then begins to search for relevant information. 
This interesting direction of development of intelligent network technologies in the future will occupy one of the most important places in the new conditions of the information society. Virtual education technologies are becoming a very effective tool for research. They make it possible to create a model for the development of many real processes and phenomena in such conditions of their real course that it is impossible or dangerous to create in reality.

In the work of the modern researcher, scientific experiment with the real objects of nature or samples of new technology is increasingly being replaced by artificially created virtual models. This saves time, energy and material costs, so it is good for science and society. But here there is a danger of replacing physical reality with the world of imagination and fantasy, which in the future may become inadequate to this reality. Rapid changes in society, due to the rapid development of information and communication technologies, make a challenge to the education system to create a new educational environment to ensure quality training of modern professionals. The educational environment is a system of psychological, pedagogical, social languages and influences, which create an opportunity to reveal the abilities and personal characteristics of the subjects of the educational environment, which have not yet been revealed. (See Fig. 1).

In the 21 st century, a new trend of social change, which has been called the virtualization of society, is becoming more noticeable. The essence of this tendency lies in the fact that today in many vital spheres of society: science, economy, politics, education more and more often there is a substitution of real things and real actions by these and other things [6].

In other words, modern society is actively creating around itself a new, imaginary world of symbols, which exists in parallel with the real physical world and becomes as much a part of being as physical reality.

The question of the scientific substantiated definition of the concept of virtual educational environment and concretization of ways of realization of the educational process within which effective use of information and communication technologies in education systems is possible gains popularity.

One of such ways is the creation and dissemination of a virtual educational environment - an open system, within which, based on the application of virtual reality technologies, effective interactive self-learning in this educational environment is provided. Of course, the virtual educational environment is a social phenomenon of real reality, but its didactic potential is not fully disclosed, because there are contradictions between the requirements of educational practice in an effective environment. An important problem is the creation of a model of the virtual educational environment and the definition of ways to optimally apply the technologies of virtual reality in the educational system.

The use of technologies of virtual reality in education has led to the emergence of a virtual educational environment, within which it is possible to carry out continuous selfrealization and self-development of free, active and creative personality in the organization of the organizations education's process.

The educational process is dominated by interactive self-study due to the presence of constant feedback in the system "teacher-student", and the organization of independent work is aimed at the development of creative skills.

Important components are ensuring the expediency of training by the priority of training before teaching; predominance of type of training; organizations of independent educational activity; increasing the motivation to learn through the use of means of complex presentation and manipulation on audiovisual information; increasing the level of emotional perception of information and developing skills to implement various forms of independent activity regarding the processing and analysis of information. 
At the same time, virtualization is often explained by processes which are neither directly nor indirectly connected to it. As a result, there is being established a disfigured idea about virtualization of social reality as about a process of transition from reality to simulacra and images. According to our opinion, the issue is not about images and not about their producing, but about the fact that they cause replacement of needs and interests of a human. Paying attention to the virtual simulacra of real phenomena and processes is aimed at distracting society from the sociocultural potential of innovation-network technologies.

To illustrate the process of innovation technologies, acquiring social features, we will present the history of creating a database of Scopus scientific journals. The Elsevier private publishing house focused on creating an informational structure enabling scholars from all over the world to obtain a fast and reliable tool producing access to innovation scientific developments and results. For several years, the commercial project had turned into a global informational network; the new network acquired characteristics which were not primarily inherent in the project. Indeed, the inclusion of a scientific journal in this base is considered to prove the quality of its materials, and presence of publications in Scopus journals is an obligatory condition for recognition of the status of a researcher as a productive scholar. The informational structure introduced by the developers turned out to be successful enough to incorporate separate, scattered, fragmented in networks, scientific publications, collections, conference proceedings on all the relevant directions of scientific activity [4].

Consequently, universities, scientific-research establishments, educational centers, research societies are joining the Scopus base and creating a certain informational medium. At the same time, though the Scopus informational network is a global one. It differs qualitatively from other networks on the Internet since the access to the database is possible only under certain conditions. The latter is oriented at preventing violation of the resource informational structure and at providing efficiency of its operation. The search system, evaluation, referee reports, relevancy, citation indices and similar tools to assure a user (a scholar, a $\mathrm{PhD}$, a student, anybody interested in the issue) that the data conform to the scientific criteria.

Virtual reality with the use of information and communication technologies in learning contributes to the formation of an interactive educational virtual environment through the use of a set of tools, methods of formation and implementation of virtual images in order to effectively interact with them as well as through faith.

Virtual educational environment, a massive and at the same time purposeful process, the development of which can be clearly seen at the present stage of development, and is an open system, which is the relationship of means and methods of new information and communication and communication interaction of all subjects of education process.

The virtual educational environment is a typical creative environment for the selfdevelopment of an open and active person, which is characterized by activity, high selfesteem, as well as freedom of thought. The virtual educational environment is dominated by the method of interactive self-learning with the constant cooperation of teaching and learning subjects in the presence of continuous feedback between them.

In the conditions of virtualization and informatization of the society modeling of the virtual educational environment serves as a basis for revealing of the potential of the modern educational environment and the possibilities of its practical embodiment in the educational process. In mass communications, the scientific community has long had the idea, according to which in many respects the discrepancy between the proposition of labor force and demand is due to the shortcomings and contradictions of the traditional system of professional education, and, first of all, its connotations. However, the most important thing 
is that it requires from the student a complete or deep immersion exclusively in the educational process so that it is better to forget about other activities.

Virtual education can lead to status-group diffusion, which involves the redistribution of intellectual and symbolic capital and involves the emergence of a kind of cyber dromomania and a culture of consumption of eclectic knowledge. Such eclectic knowledge becomes the basis for the preparation of student research papers (abstracts, term papers and dissertations), which reduces the level of their academic culture and contributes to the devaluation of epistemic research, turning the latter into amateur and scientific journalism [9].

Thus, according to the researcher, teachers of about 250 largest European higher education institutions in 37 countries actively and purposefully use different types of electronic resources working with students. At the same time, most European higher education institutions (91\%) offer blended student education.

About $82 \%$ of European higher education institutions offer the optional courses implemented in cyberspace through information and communication technologies. Among the EU countries, only 3\% of higher education institutions do not use information and communication technologies with the motivation of lack of financial opportunities and deficient competence of the teaching staff in the field of creating electronic educational and methodological complexes in the disciplines [5].

The opinion of students and employers about e-learning on the basis of a mixed model is also consolidated for $60 \%$ of respondents who study in the largest institutions of higher education in the United States.

According to The Sloan Consortium, respondents believe that blended learning is more effective than traditional learning. This view is supported by the majority of US education managers (70\%), who, according to statistics from the Online Learning Consortium, believe that the level of quality of interactions between teachers and students through information and communication resources and cyberspace is higher than the model traditional teaching $[3 ; 4]$.

The social dialogue between the Australian Ministry of Education and employers indicates the need and interest of the domestic labor market in the growth of graduates' information culture and the number of target audiences for e-higher education and elearning technologies.

Summarizing the results of global research on the use of information and communication technologies in higher education institutions in Europe and America, M. Lomonosova argues that most institutions seek in one way or another to involve students in the use of cyberspace resources and maximize the effectiveness of "virtual reality" in higher education [8].

The problem of empirical research is the existing contradiction between the need for the introduction of e-learning technologies in higher education and the current state of its provision with the appropriate tools at the National Aviation University.

The first block of questionnaires concerns the level of relevance of the introduction of electronic technologies in the educational process, their significance and typical problems of implementation. As becomes clear from Fig.1, respondents prefer mixed, distance and elearning models that correspond to the highest type of mobility in the information society and the emergence of a special kind of it, which is called the cybermobility.

The package of questions, the distribution of opinions on which is illustrated in the diagrams, allows to assess the priority orientations of respondents on the most effective models of training in free economic education, the importance of certain advantages of etechnologies in terms of survey participants, the main obstacles to e-learning. 


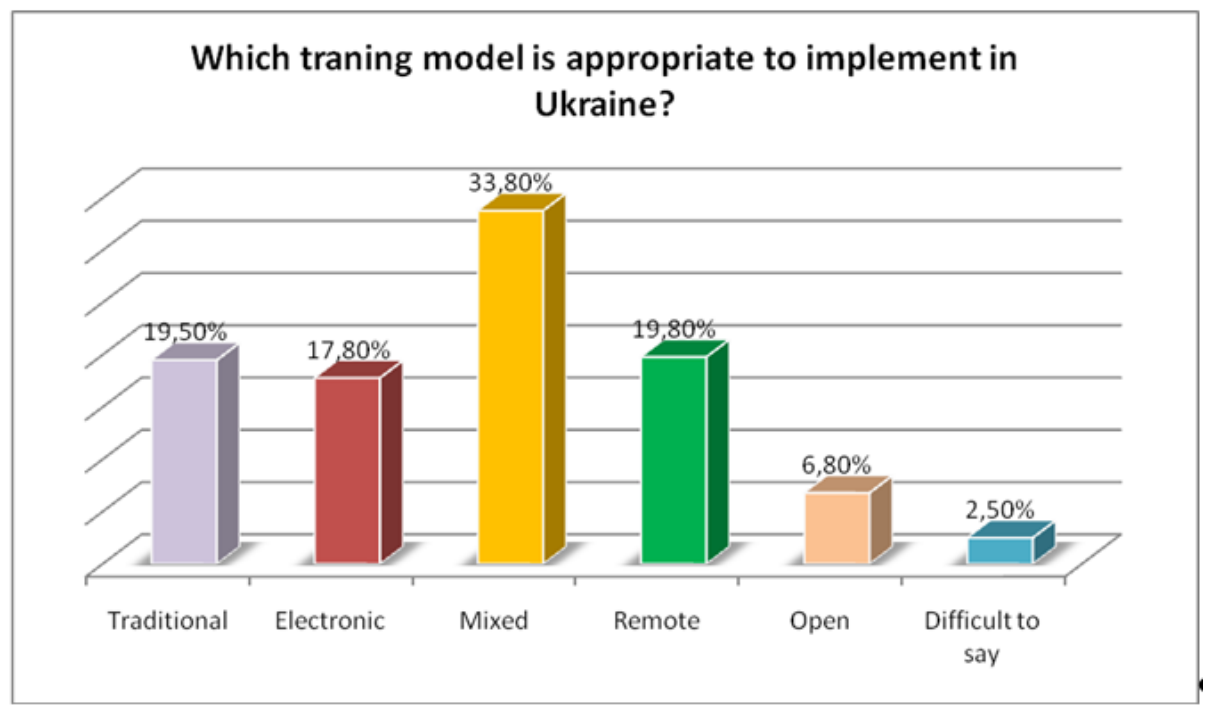

Fig. 1: Training models

Thus, $38 \%$ of respondents among students consider the introduction of e-education appropriate, while there is an increase in the percentage of people who believe that the introduction of e-education is most appropriate in the transition from undergraduate to graduate and $\mathrm{PhD}$.

Among teachers, up to $20 \%$ of respondents noted an increase in the component of eeducation costs and the effect of losing student audiences (15.1, 16.7 and 14.8\%, respectively), which indicates different expectations for e-education. Teachers assess its implementation as problematic rather in the financial aspect, to which are added the possible losses of the student audience. Such assessments may be related to concerns about the reduction of teaching staff due to the introduction of information technology. At the same time, the number of respondents who consider the introduction of e-education inexpedient is constantly growing (from 10.9 to $22.9 \%$ ). This confirms the hypothesis of the presence of status differences in relation to e-education.

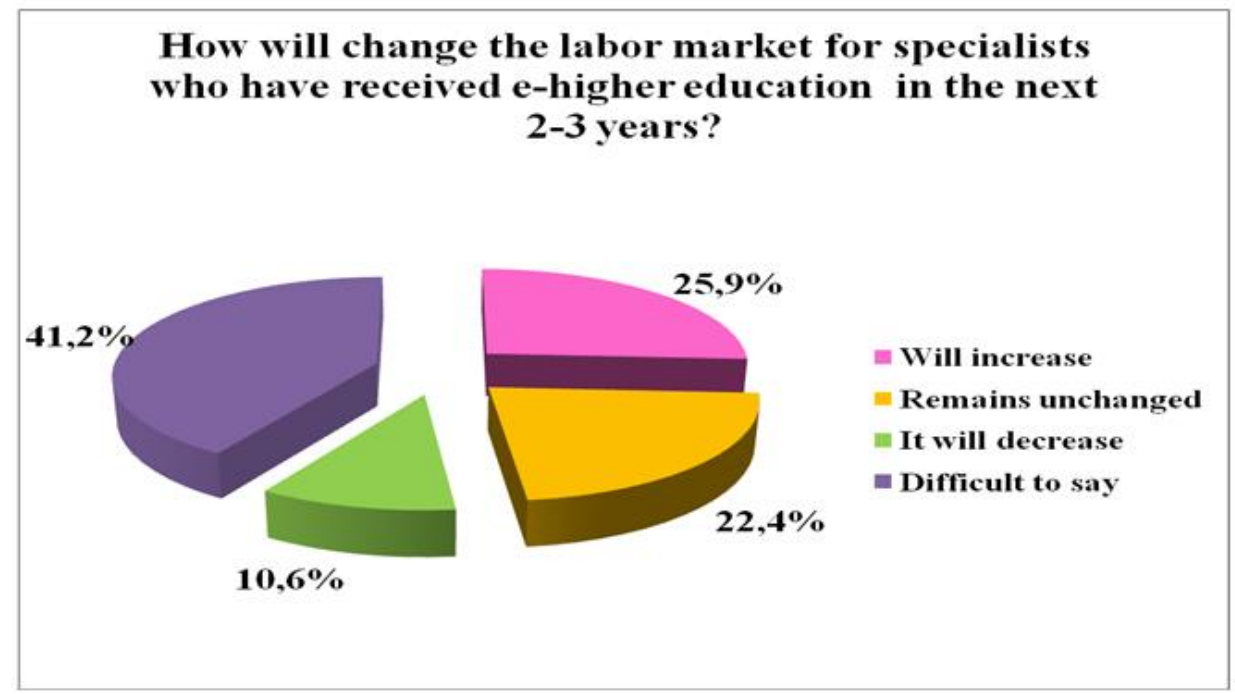

Fig. 2: Dynamics of change the labour market 
It should be noted that the use of e-education is not limited. The forecast for the demand for professionals who receive education in this way is cautiously optimistic $(41.2 \%$ chose an uncertain answer "difficult to say"), but a significant number of respondents are convinced that it already exists (although due to the action of various reasons) a powerful target audience for which e-learning is most desirable (Fig. 2).

Thus, this conclusion is confirmed by the data of the fourth block of questions concerning the forecasting of demand for e-higher education and its potential target audience. The answers provided an opportunity to verify the hypothesis of empirical research on the relationship of a number of individual characteristics of the participant of such an audience with the relevance of the use of e-higher education by certain social contingents.

Leaders of the target audience of e-higher education, according to respondents, are mobile students and military children (20.3\%), people with physical, physiological or emotional problems $(15.0 \%)$, people who are geographically isolated in relation to the educational needs they need.

So, at the answers of the respondents there is a statement of a rather low level of technical support of free economic education by means of e-learning. The highest security positions have access to $\mathrm{WiFi}$, computer classes with Internet connection, access to electronic resources of the library and internal e-mail (24.2, 15.8, 15.0 and 10.0\%) [7].

\section{Factors that discourage the use of distance learning in your department}

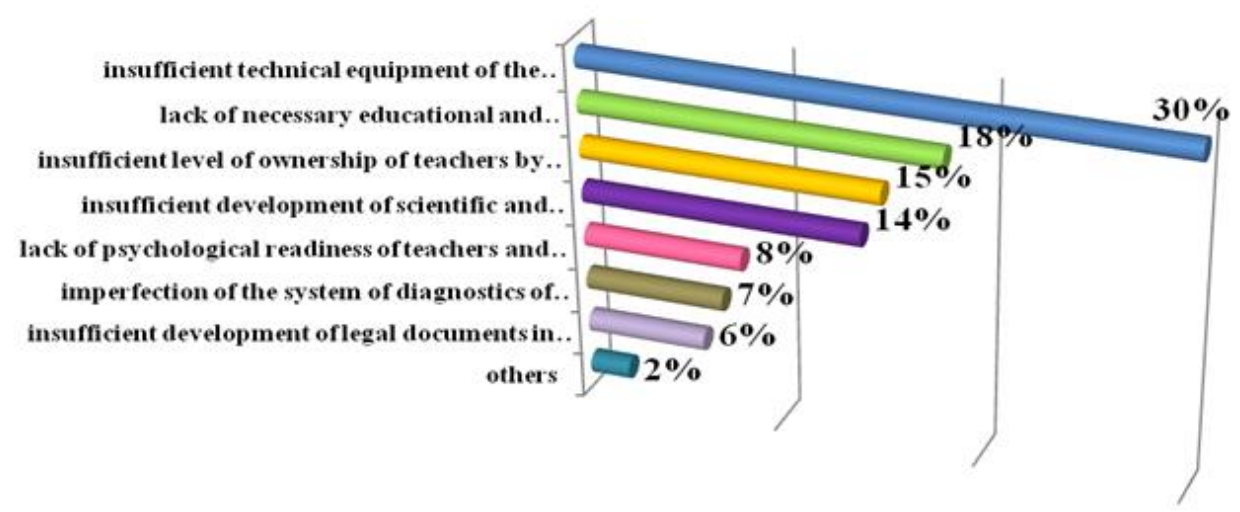

Fig. 3: Factors that discourage the use of distance learning

It is clear, that NAU, as well as most of the institutions of higher education of technical profile, were created to meet the needs of the industrial economy, whose technologies are inadequate for training in the conditions of information civilization (Fig.3). 


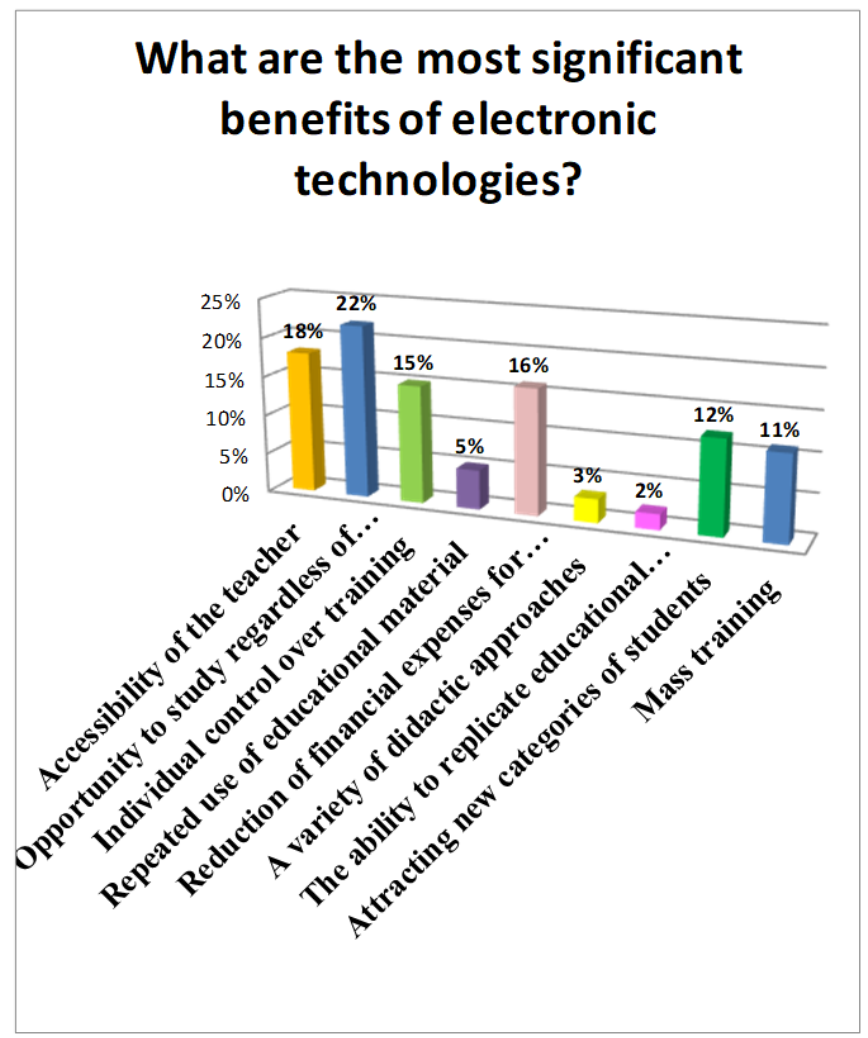

Fig. 4. The benefits of electronic technologies

Thus, according to the results of our study, one of the set of problems of practices of introduction of electronic technologies of training at the National Aviation University and the State University of Telecommunications, first of all, the information culture of the teaching staff.

The information culture includes a number of competencies:

1) operational and technical (knowledge and skills necessary for the correct identification of information and performance of a particular task or problem; effective search of information; its organization and reorganization);

2) logical-analytical (ability to interpret and analyze the information obtained, assess its accuracy and reliability);

3) moral and ethical (compliance with ethical standards for the use of information);

4) socio-communicative (organization of network communities and maintaining contacts in these communities to convey and present the results of analysis and interpretation to others, further use of information to perform certain actions and achieve certain results) (Fig. 4).

Cybermobility characterizes the type of activity of social groups that occurs in weak connection with the physical space of production and other activities. This confirms the first hypothesis of the study, according to which, among the student and pedagogical community most respondents associate the importance of computerized education with opportunities for cross-border mobility, individualized knowledge control and reduced economic costs (compared to traditional education).

For the younger generation, the use of electronic technologies is a given of their everyday micro-level life, which may partially deactivate their use at the macro level. In 
addition, the respondents of the student part of the sample are better adapted to the use of various mobile electronic devices (tablets, androids, laptops, etc.) compared to teachers.

For respondents in the senior subgroup of the sample, who are closer in time to $\mathrm{PhD}$ and doctoral studies, free possession of devices that are technically necessary for the use of electronic technology, often becomes difficult due to age and a certain habit focused on traditional education with a predominance of physical media information over electronic. This explains the differences from 4 to $7 \%$ in the respondents' choice of answer options regarding the high and highest expediency of the introduction of electronic technologies.

The results of the survey indicate the existence of actual backwardness in the promotion of the latest learning technologies, regardless of the content and profile of education. The consequences for technical professionals, however, are more disastrous than for sociohumanitarian professionals.

Cybermobility characterizes the type of activity of social groups, which is insignificantly related to the physical space of production and other activities. This confirms the first hypothesis of the study. It is also recorded that the respondents-teachers tend to use distance education as an auxiliary: in reading certain distance courses $(25 \%)$, advanced training and retraining of specialists $(20 \%)$ and pre-university training of entrants $(12 \%)$.

\section{Conclusion}

The information economy, which is characterized by information speed and index (quality of communications and their "share" in society), corresponds to the professional structure of society, where there are key status groups - producers and consumers of information. The social consequences of the introduction of electronic (information and communication) technologies are: 1) the transition from the production of goods to the production of information in modern society; 2) the growth of the applied value of science; 3) determinism of social development by the informatized industry. It is determined that the formation of a single network of electronic communications becomes a factor of sociocultural changes, the content of which is to limit human autonomy and turn it into a real global participant in events that take place anywhere in the world. This revolution is taking place in a sequence from television (through the creation of global accomplices - viewers and observers) to the Internet (through the transformation of viewers into interactive coactors).

Informatization is currently a direction of globalization of education, which is realized through continuous self-education and development of all aspects of informatization, from large information portals, databases and Internet resources to new educational technologies such as distance learning, Internet universities, Internet laboratories etc.

Within the framework of the third task, it is proved and established that the informatization of education leads to certain social consequences. These include: the formation of a system of continuing education aimed at the formation of socio-role flexibility and variability due to local competencies and fragmented professional consciousness of technical specialists; creation of socio-professional niches that require mastering certain repertoires and scenarios of professional activity, not professions; change of social and role features of teacher-student interaction. This interaction should be considered as a component of horizontal-network status-role structures that are formed in a globalized society on their own initiative and ending with state-initiated reforms, Westernization as a direction of change in the cultural and historical component of higher education; marketing of higher education. 


\section{References}

1 Burd'e, P., Sociologiya social'nogo prostranstva. M.: In-t eksperimental'noj sociologii. SPb.: Aletejya., 2007, pp. 288.

2 Clark, B. Diversification of Higher Education. The Mockers and Mocked: Comparative Perspectives on Differentiation, Convergence and Diversity in Higher Education. Surrey: Pergamon, 1996. pp. 29-43.

3 Gaebel, M., Colucci, E., Kupriyanova ,V., Morais, R. E-learning in European higher education institutions. Brussels: EUA Publications, 2014. 92 p.

4 Garrison, D., Vaughan, N. Blended learning in higher education: Framework, principles, and guidelines. Jossey-Bass. 2008. 272 p.

5 Lewis, M., McArthur, D. Untangling the Web: Applications of the Internet and Other Information Technologies to Higher Learning. Santa Monica: Rand, 1998. 114 p.

6 Margolis, M. Brave New Universities. First Monday. 1998. Vol. 3. № 5. URL: http://www.firstmonday.dk/issues/issue35/margolis/index.html.

7 Polovaya, N., Liasota, L., Strihul, M.. Transport education in the higher education system within the context of modern socio-economic processes. Aviation in the XXI-st century: the eighth world Congress. Kyiv: NAU, 2018. pp. 13.3.42-13.3.46. URL: http://conference.nau.edu.ua/index.php/Congress/Congress2018/paper/viewFile/5017/4205.

8 Stryhul M., Khomeriki O., Yahodzinskyi S., Lyasota L., Semenets-Orlova I. Peculiarities of development and dynamics of economism and the commercialization of Ukrainian higher education. Problems and Perspectives in Management. Volume 17. 2019. Issue 2. pp. 289-302.

9 Stryhul, M., Khomeriki, O., Kovalenko, O., Perelyhin, T. Communication in the System of Information Space through the Sociological Analysis. CEUR Workshop Proceedings. CMiGIN 2019. Conflict Management in Global Information Networks Proceedings of the International Workshop on Conflict Management in Global Information Networks (CMiGIN 2019) co-located with 1st International Conference on Cyber Hygiene and Conflict Management. pp. 530-542. 